\title{
A note from the SBMAC
}

\section{BERNARDES ${ }^{1}$, C. T. L. S. GHIDINI ${ }^{2}$, C. HOPPEN ${ }^{3}$,} A. R. L. OLIVEIRA ${ }^{4}$ and P. M. RODRIGUEZ ${ }^{5}$

Trends in Computational and Applied Mathematics (TCAM) is a new journal published by the Brazilian Society for Computational and Applied Mathematics (SBMAC).

SBMAC was established in 1978 as a scientific organization aimed at developing and promoting Computational and Applied Mathematics in Brazil. It is a leading environment for researchers, professionals and students working in Applied Mathematics and related fields. Currently, SBMAC has over 300 members and it organizes the largest scientific e vent in this field in Latin America, the National Congress of Computational and Applied Mathematics (CNMAC), an annual congress that attracts around 700 attendees. Furthermore, SBMAC organizes regional events and co-sponsors many other events in Brazil.

In 1999, SBMAC created the journal Tendências em Matemática Aplicada e Computacional (TEMA), which was originally devoted to papers presented at CNMAC and to the dissemination of Applied Mathematics in Portuguese. With the publication of 21 volumes, the journal has grown and has become a leading Brazilian journal in the field. In the past few years, the great increase in the number of submissions in English, by Brazilian and foreigner researchers alike, shows that TEMA has attracted an international audience and is recognized as an important publication in Computational and Applied Mathematics.

The new journal, Trends in Computational and Applied Mathematics, marks the rebirth of TEMA as a truly international journal, yet one that preserves its history and the high profile that it has achieved. Our goals are to publish original research, theoretical developments and case studies

\footnotetext{
${ }^{1}$ Universidade Tecnológica Federal do Paraná (UTFPR), Cornélio Procópio, Paraná, Brazil - E-mail: mbernardes@utfpr.edu.br https://orcid.org/0000-0003-3366-122X

${ }^{2}$ Universidade Estadual de Campinas (UNICAMP), FCA, Campinas, São Paulo, Brazil - E-mail: carla.ghidini@fca.unicamp.br https://orcid.org/0000-0002-5018-8932

${ }^{3}$ Universidade Federal do Rio Grande do Sul (UFRGS), Porto Alegre, Rio Grande do Sul, Brazil - E-mail: choppen@ufrgs.br https://orcid.org/0000-0002-7581-1583

${ }^{4}$ Universidade Estadual de Campinas (UNICAMP), IMECC, Campinas, São Paulo, Brazil - E-mail: aurelio@ime.unicamp.br https://orcid.org/0000-0002-6471-4710

${ }^{5}$ Universidade Federal de Pernambuco (UFPE), Recife, Pernambuco, Brazil - E-mail: pablo@de.ufpe.br https://orcid.org/0000-0003-0016-2360
} 
on promising themes; to offer an interdisciplinary and reliable international forum; to provide an efficient peer-review system, leading to a fast response time to the first decision.

For forthcoming issues of TCAM, we invite researchers in Applied Mathematics and related fields to submit papers with innovative and/or relevant contributions to Computational and Applied Mathematics.

We hope you enjoy reading the first issue of the new TCAM. We are looking forward to receiving your future contributions, as well as any comments and suggestions you may have. We will try our best to adjust to the expectations of our readership. 